\title{
Aortic Balloon Valvotomy
}

National Cancer Institute

\section{Source}

National Cancer Institute. Aortic Balloon Valvotomy. NCI Thesaurus. Code C99916.

Dilation of the valve between the left ventricle of the heart and the aorta by inflating a balloon. (ACC) 